\title{
The Effect of Urban Street Gang Densities on Small Area Homicide Incidence in a Large Metropolitan County, 1994-2002
}

\author{
Paul L. Robinson, W. John Boscardin, Sheba M. George, \\ Senait Teklehaimanot, Kevin C. Heslin, \\ and Ricky N. Bluthenthal
}

\begin{abstract}
The presence of street gangs has been hypothesized as influencing overall levels of violence in urban communities through a process of gun-drug diffusion and crosstype homicide. This effect is said to act independently of other known correlates of violence, i.e., neighborhood poverty. To test this hypothesis, we independently assessed the impact of population exposure to local street gang densities on 8-year homicide rates in small areas of Los Angeles County, California. Homicide data from the Los Angeles County Coroners Office were analyzed with original field survey data on street gang locations, while controlling for the established covariates of community homicide rates. Bivariate and multivariate regression analyses explicated strong relationships between homicide rates, gang density, racelethnicity, and socioeconomic structure. Street gang densities alone had cumulative effects on small area homicide rates. Local gang densities, along with high school dropout rates, high unemployment rates, racial and ethnic concentration, and higher population densities, together explained $90 \%$ of the variation in local 8-year homicide rates. Several other commonly considered covariates were insignificant in the model. Urban environments with higher densities of street gangs exhibited higher overall homicide rates, independent of other community covariates of homicide. The unique nature of street gang killings and their greater potential to influence future local rates of violence suggests that more direct public health interventions are needed alongside traditional criminal justice mechanisms to combat urban violence and homicides.
\end{abstract}

KEYWORDS Violence, Injury, Mortality, Intentional injury mortality, Homicide, Gangs, Street gangs, Crime, Youth violence, Health disparities

\section{INTRODUCTION}

Homicide is a leading cause of death in the USA, although its impact on racial and ethnic minority groups tends to be greater. In 2003, homicide ranked 20th for Whites as compared to 6th for African Americans, 7th for Latinos, and 11th for Native Americans and 14th for Asians and Pacific Islanders. ${ }^{1}$ In the USA, rates of homicide have remained persistently highest for African Americans living in urban

Robinson, George, Teklehaimanot, and Heslin are with the Charles Drew University of Medicine and Science, Los Angeles, CA, USA; Robinson and Heslin are with the University of California, Los Angeles, Los Angeles, CA, USA; Bluthenthal is with the Urban Community Research Center, Sociology Department, California State University, Dominguez Hills, Carson, CA, USA and with the Health Program, RAND Corporation, Santa Monica, CA, USA; Boscardin is with the University of California, San Francisco, San Francisco, CA, USA.

Correspondence: Paul L. Robinson, Charles Drew University of Medicine and Science, Los Angeles, CA, USA. (E-mail: paulrobinson@cdrewu.edu) 
but higher than White and Asian rates. For both African Americans and Latinos, the elevated homicide rates are driven by violence occurring among young males living in certain types of social and territorial environments. ${ }^{3-5}$

\section{Theoretical Perspectives on Homicide: Structural Factors and Social Disorganization}

Proponents of structural approaches see violent behavior and homicide as resulting from structures and processes that lead to (a) the breakdown of social control, which frees individuals to commit violent acts, and/or (b) internalized social strains that are linked to social disorganization, relative deprivation, and neighborhood environmental conditions. ${ }^{6-10}$ Specific structural characteristics that have been associated with homicide include economic disadvantage, high unemployment rates, and racial segregation. ${ }^{11-17}$ These structural forces have been shown to influence community violence and homicide rates via more proximal processes such as local associational networks and ties, variations in social capital, and community collective efficacy. ${ }^{18-22}$ In some neighborhood areas, weak local social institutions simultaneously deemphasize cultural values and social norms, while leaving individuals subject to market-based imperatives. As a result, some engage in instrumental crime and violence in response to anomic pressures thus creating the observed local variations in community rates of violence. ${ }^{23,24}$ Failures and negative experiences at home, in foster homes, in educational institutions, jails, and prisons have been associated with the individual propensity of juveniles to act aggressively and commit violence. ${ }^{25-29}$

\section{Street Gang Homicide: A Special Case of Murder}

When compared with homicides in general, street gang killings tend to exhibit greater (1) spatial concentration, (2) firearms use, (3) involvement of young African American or Latino male perpetrators and victims and are more likely to occur outside (including in a car). Street gang homicides are also more likely to include innocent bystanders and unrelated victims. ${ }^{30-32}$ Although street gang homicides typically contribute less than half of the homicides that occur in a given metropolitan area, evidence is emerging that their overall effect on rates on lethal violence may be greater. In Chicago, for example, gang-motivated homicides were approximately $25 \%$ of all homicides occurring in that city between 1993 and 1995..$^{33}$ In Saint Louis between 1993 and 1998, gang homicides accounted for anywhere from $25.5 \%$ in 1994 to $7 \%$ in $1998 .{ }^{34}$ In Los Angeles County during 1994 and 1995, gang-motivated homicides accounted for $45 \%$ of all homicides. ${ }^{35}$ The city-to-city differences in the proportion of gang homicides are in part due to differences in the way that gang homicides are reported. For example, Los Angeles uses a liberal definition that includes all crimes that involved a gang member or a gang motive; however, in Chicago, a crime must have had the furtherance of the gang as its main motivation to be classified as gang related. ${ }^{36}$

Among the most important features of street gangs that negatively impact public health in community areas are the impacts that simple proximity to the places where street gangs congregate are having on overall rates of interpersonal violence in the surrounding area. Research in Chicago that tracked homicides by weapon type over time (1980-1995) and space (census tracts) found that there is a core-periphery pattern to lethal violence in neighborhoods within that city. The most lethal communities in Chicago fell within territories associated with the Vice Lords and the Gangster Disciples, two of the city's largest street gangs, while more moderately violent areas formed a "buffer" between the most lethal communities and areas of Chicago with low homicide rates. ${ }^{37}$ 
In Chicago during this period, increased lethality of violent encounters was associated with a process of weapon substitution whereby the proportion of homicides inflicted by "street guns" (handguns or semi-/fully automatic weapons) rose with increasing proximity to the core gang areas. This pattern suggested a "defensive diffusion" process whereby residents of communities near the gang centers armed themselves in response to the influx of street guns into gang plagued areas and the perceived threat that this created. Street guns are among the most efficient killing machines available, and to the extent that they are available, lethal violence will increase as other weapons (knives, blunt objects, etc...) are replaced by street guns. This weapon substitution process is associated with higher overall homicide rates. ${ }^{37}$

Gang-motivated violence has been shown to occur in response to the perception of "threat" by rival groups of youth in nearby neighborhoods. Recent work in Pittsburgh, PA has demonstrated that the presence of gang "set space" (places where gang members routinely congregate) serves as a crime generator and catalyst for increased levels of lethal violence in areas that are proximal to these gang set spaces. ${ }^{38-40}$ A 1999 study of gang-motivated homicides in St. Louis concluded that for crime where the furtherance of the gang is the primary motivation, the effect of gangs exhibited a "contagion" effect that could not be fully attributed to clustering of social disadvantage and racial/ ethnic concentrations. Instead, it was found that the spatial distribution of gangmotivated homicides likely reflected processes intrinsic to presence and activities of gangs (i.e., turf rivalries) rather than the underlying social and economic characteristics that more comprehensively explain other types of homicides. ${ }^{41}$

Given the potential negative spillover effects of local gang rivalries on nearby communities due to processes such as weapon substitution and cross-type diffusion of homicide, we hypothesized that community areas in Los Angeles with higher densities of nearby potential rival gangs would experience greater levels of homicides, even after controlling for other factors already known to influence community homicide rates. We tested this hypothesis in Los Angeles County, CA, a large metropolitan area with an estimated 1,108 street gangs and 85,298 members, ${ }^{42}$ over an 8-year period (1994-2002), a period when homicide rates declined steeply both in the Los Angeles area and nationally.

\section{METHODS}

\section{Study Area: Los Angeles County, 1994-2002}

Los Angeles County, CA is the largest US county in terms of population $(9,519,338)$ and one of the largest in land area $\left(4,061\right.$ miles $\left.^{2}\right) .{ }^{43}$ Two hundred eighty-nine zip code tabulation areas existed in Los Angeles County at the 2000 census. We selected 255 of those zip codes to merge with homicide mortality data and other covariates for analysis. We excluded zip codes with very low populations and several large university campuses that had their own zip codes. The resulting analytic sample comprised $88 \%(255 / 289)$ of the county's zip codes and contained $98.9 \%$ of all persons who resided in Los Angeles County in 2000 and $98.9 \%$ of all homicide victims residing in Los Angeles County during the years 1994-2002.

\section{Study Population}

All persons who resided in Los Angeles County during the years 1994-2002 and became victims of homicide comprised the universe of observations. Annual counts 
of individual deaths due to homicide were extracted from the Los Angeles County Department of Health Services mortality database using International Classification of Diseases (ICD), Ninth and Tenth Revision group death codes (ICD9-E960-E969; ICD10-338 through 346) to subset only those deaths attributed to intentional injury. The resulting analysis file contained a record for each death along with the age, gender, race, and zip code of residence of the victim.

The data were used to calculate both age-adjusted mortality rates and a geographic measure of homicide incidence over the study period. An 8-year homicide incidence rate was calculated using the number of homicides per square mile (1994-2002) in a zip code as an outcome measure for the multivariate analysis, while controlling for population density to account for rural-suburban-urban differences in zip code and population sizes. Additionally, we derived 8-year ageadjusted rates by summing homicide victims and population counts for the 8 years of study to year 2000 zip code boundaries and using the direct standardization method against the overall Los Angeles County age distribution from the 2000 census. Although sensitivity testing of this outcome variable produced similar results to those presented below, we felt that the fact that we lacked zip code level intercensual population data $(1994,1995,1996$, etc...) would leave the research open to the criticism that the denominator of 2000 population by age did not match the periodicity of the numerator, the annual mortality counts. To avoid a debate over the implications of using a cross-sectional population denominator, we adopted the square miles of the zip code as a more stable denominator as the zip codes in our sample had highly stable boundaries during the entire study period. For comparative purposes, we also report any major differences in results between these two outcome measures that emerged in the multivariate analysis.

\section{Predictor Variable-Street Gang Density Surrounding Population Centers}

As discussed above, conflicts between rival street gangs in areas of Los Angeles County contribute a substantial proportion of homicide deaths in and around their territorial claims and also influence local rates of non-gang-related homicides. Rivalries between and within African American street gangs (Blood and Crip sets), along with conflict between and within Mexican-American street gangs (various Sureno sets under the influence of the Mexican Mafia), along with drug and turf conflicts involving Central American gangs (i.e., Mara Salvatrucha, otherwise known as MS-13) all influence homicide rates in Los Angeles County. Thus, we derived a variable for the Density of Street Gang Activity surrounding populations by measuring the number of African American and Latino street gangs that existed within a 2-mile radius of each zip code's population-weighted geographic centroid. This provided a measure of the population center of each zip code's potential for contact with gang activity and gang turf conflict. The gang analysis file was constructed using Arc View GIS and Arc Info Workstation (ESRI, Inc., Redlands, CA, USA) using highly accurate geographic data compiled from original ethnographic and observational field research conducted by the University of Southern California geography department between 1996 and 2006 to map out all major Black and Latino street gang boundaries in Los Angeles County. ${ }^{44}$ The geographic boundaries of each gang were originally captured as a geographic polygon file, but for our analysis, the geometric centroid of each gang's polygon was calculated to provide a single point that indicated the presence of a street gang territory. The 
number of street gang points within a 2-mile radius of each population-weighted zip code centroid point was calculated and used as the street gang density measure.

\section{Control Variables-Known Sociological Predictors of Community Violence}

Our control variables were selected based on previous research on community predictors of violence. ${ }^{45}$ Attachment to the educational process and educational attainment have shown consistent effects on the development of violent behavior. ${ }^{46,47}$ To capture this effect, we included a derived variable to specifically measure failures in local secondary educational institutions. This variable, Dropout Rate, was calculated using the average dropout rate (1994-1999) for all high schools within 5 miles of each zip code's centroid. To address the potential relationship between foster care placement activity and exposure to violence, we calculated the Foster Rate-the rate per 1,000 of children living in that zip code that were placed in out of home foster care in 1998, the only year for which this data was available.

Homicide rates are significantly higher for African American and Latino males when compared to Whites and Asians. Two variables were used to control for these trends, Percent Black-percent African American population for that zip code in 2000 and Percent Hispanic_-percent Hispanic population for that zip code in 2000. Density of land use and crowding is known to influence community homicide rates; thus, the variable Population Density, persons per square mile in that zip code in 2000, was used to control for this phenomenon.

Known relationships between lack of material resources, unemployment, age, family structure, and levels of homicide in a community were controlled for using Median Income-the median household income for that zip code in 2000, Youth Age 15-24-the percent of persons age 15-24 in that zip code in the year 2000, Female Headed - the percent of households headed by females in that zip code in 2000, and Unemployment - the unemployment rate for 2000 in that zip code.

\section{Methods for Data Analyses}

Statistical analyses were conducted, using the SAS statistical analysis program (SAS Institute Inc., Cary, NC, USA). Skewed variables were logarithmically transformed to provide normality. Initially, descriptive statistics and bivariate analysis of the identified variables were conducted to assess the independent relationships between each independent predictor and homicide rates per square mile. Secondly, the entire set of covariates was regressed to assess each variable's independent explanatory power on 8-year homicide trends in Los Angeles County. The regression model was adjusted for the effects of spatial autocorrelation using the SAS Proc Mixed with repeated measures of spherical clustering, based on the state plane coordinate system in miles, using a 3-mile lag distance. This procedure corrected the standard errors and significance tests to provide a robust estimate of the significance of the observed associations despite any geographical clustering.

\section{RESULTS}

\section{Overall Homicide Trends in Los Angeles County, 1994-2002}

A good way to initially approach territorial differences in community homicide incidence rates in Los Angeles County, CA is to consider trends for the eight county 
administrative districts known as "Service Planning Areas" (SPA). Table 1 shows the distribution of homicides across age and race by SPA.

There were 10,880 residents of Los Angeles county who became homicide victims in our zip code sample between the years 1994 and 2002. The South SPA was the persistent epicenter of homicide with average annual age-adjusted rates exceeding 40 homicides per hundred thousand persons. Youth homicide rates, in particular, were extremely high in the South SPA. Consistent with national trends, African Americans and Latinos countywide had higher rates than Whites/other race individuals. However, rates are elevated for all races/ethnicities living in the South SPA, suggesting a territorial effect. The territorial clustering of high community homicide rates and their spatial coincidence with gang territories is made more evident by Figure 1. With few exceptions, areas with higher concentrations of street gangs exhibited elevated rates.

\section{Bivariate and Multivariate Relationships between Known Predictors and Homicide Rates in Los Angeles County}

As shown in Table 2, zip codes with more than ten street gangs within a 2-mile radius of that zip's population-weighted centroid contained $40 \%$ of the homicides observed during the study period, despite having only $16 \%$ of the county's population. There was a positive linear relationship between the street gang densities surrounding the population center of a zip code and both the number of homicides per square mile and the age-adjusted homicide rate in the zip code. Bivariate regression indicated that when considered individually, all of the covariates identified in the existing literature as influencing community homicide rates were highly significant predictors of local variations in homicides per square mile (0.0001-0.0077; Table 3).

Our multivariate models exhibited even stronger relationships, explaining over $90 \%$ of the zip code variability in 8 -year homicide incidence. Street gang density and the dropout rate in nearby high schools remained significant in the overall multivariate model, along with race/ethnic composition and unemployment (Table 4).

When the outcome variable was disaggregated by race, only population density and street gang density were consistently significant across the three racial/ethnic groups. Interestingly, while living in areas with higher proportions of Latinos is not associated with higher homicide rates for African Americans, the reverse situation does increase homicide rates for Latinos. High school dropout rates in nearby high schools influenced homicide patterns for African Americans and Whites/others, but not for Latinos. Household income and family structure as measured by the percent of households that are headed by females influenced White homicide rate, but not the other two groups. It is important to note that when disaggregated by race, the White model has much weaker explanatory power $\left(R^{2}=0.52\right)$ when compared to the disaggregated Black or Hispanic models.

For the purposes of sensitivity testing, we replicated our analysis in three different ways. (1) We substituted homicide rates for homicides per square mile. When this was done, population density was no longer significant, high school dropout rate within 5 miles was no longer significant, percent aged 15-24 became significant at 0.05 in a negative direction, and the overall model was weaker $\left(R^{2}=\right.$ 0.77); all other results were comparable to the square mile-based model. (2) We used Geoda 9.x to create a maximum likelihood estimation with a nearest neighbor spatial lag. The only difference in this model was that female-headed households 


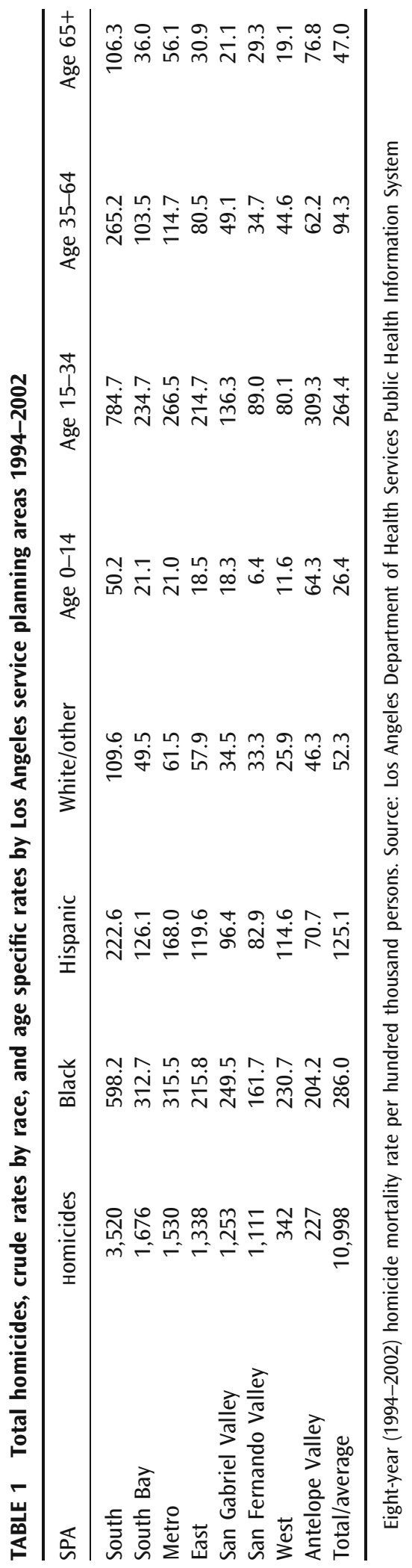




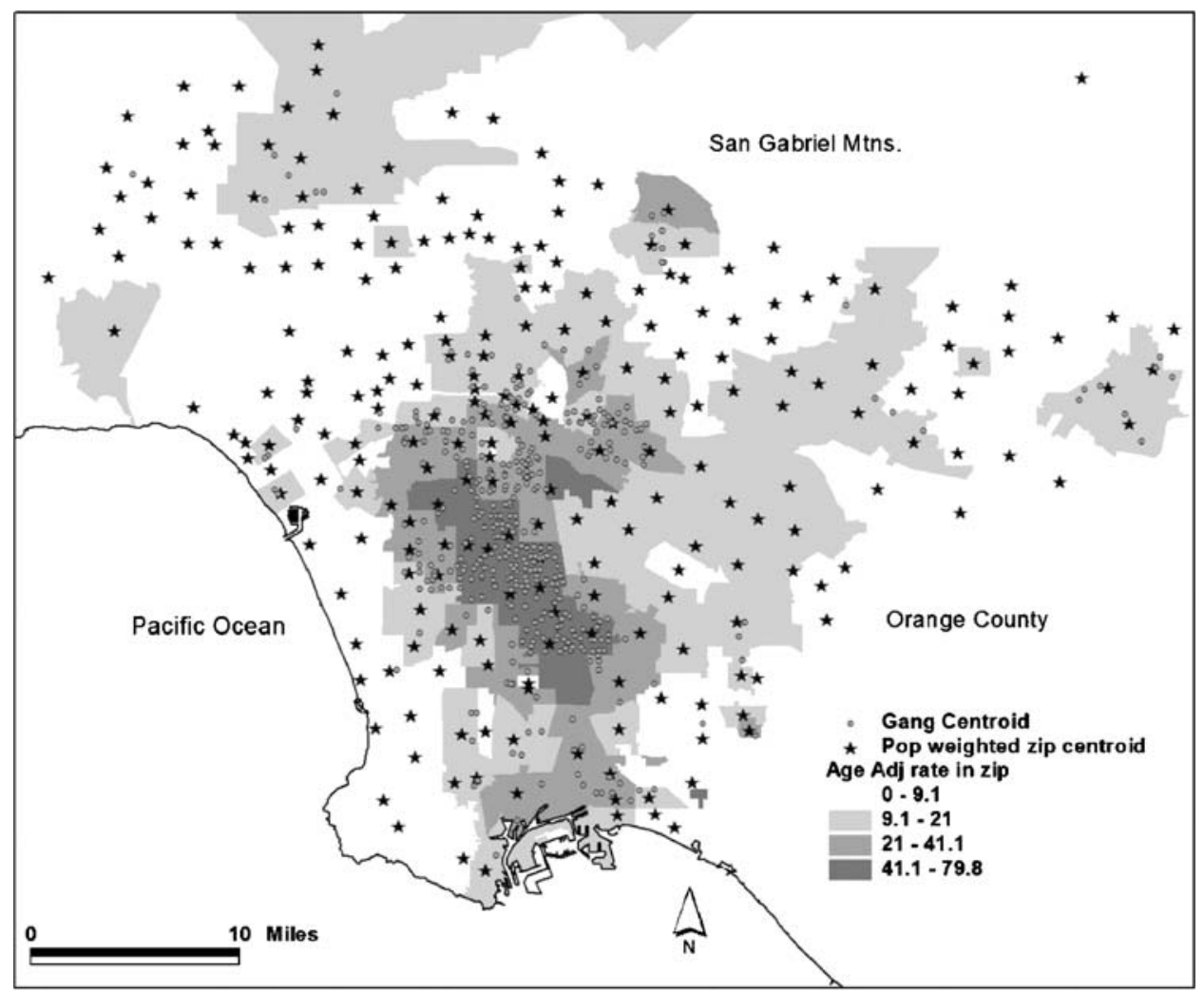

FIGURE 1. Zip code population centers, gang centers, and age-adjusted homicide rates, Los Angeles County 1994-2002.

became significant, and unemployment rate and 5-mile dropout rate lost significance. All other variables in this model had comparable significance and effect sizes to our spatial error model, and the $R^{2}$ remained at 0.90 . (3) We replicated the model using a robust zero-truncated negative binomial regression model to see if the results held up under the negative binomial distribution. Again, this model yielded results that were highly similar to our spatial error model. The only difference is that the 5mile dropout variable lost significance. All other variables had comparable significance levels and effect sizes to our ordinary least square spatial error model. The results of these sensitivity checks give us a high degree of confidence that our analysis is both reliable and accurate.

TABLE 2 Relationships between gang density and homicide (descriptives)

\begin{tabular}{lcccc}
\hline $\begin{array}{l}\text { \# of street gangs }<2 \\
\text { miles away }\end{array}$ & $\begin{array}{l}\text { Population } \\
\text { 2001 }\end{array}$ & $\begin{array}{l}\text { Homicides } \\
1994-2002\end{array}$ & $\begin{array}{l}\text { Mean \# of homicides } \\
\text { per square mile }\end{array}$ & $\begin{array}{l}\text { Five-year age-adjusted } \\
\text { rate }\end{array}$ \\
\hline 0 & $4,307,634$ & 2,542 & 3.4 & 58 \\
$1-10$ & $3,611,640$ & 3,991 & 11.5 & 103.9 \\
$11-20$ & 643,024 & 1,189 & 29.1 & 205.8 \\
$21-30$ & 444,490 & 1,319 & 41.8 & 305.7 \\
$30+$ & 468,893 & 1,839 & 61.1 & 438.1 \\
\hline
\end{tabular}


TABLE 3 Bivariate relationships between homicide per square mile and individual predictors derived from the literature

\begin{tabular}{lcc}
\hline Variable & Beta effect & Adjusted $R^{2}$ \\
\hline Population Density & $2.07^{* *}$ & 0.61 \\
Foster Care Rate & $0.86^{* *}$ & 0.78 \\
African American, Latino Street Gang Density & $0.53^{* *}$ & 0.78 \\
High School Dropout Rate within 5 miles & $0.61^{* *}$ & 0.63 \\
Percent African American & $0.60^{* *}$ & 0.76 \\
Percent Latino & $0.69^{* *}$ & 0.74 \\
Percent Ages 15-24 & $2.04^{* *}$ & 0.73 \\
Median Income & $-1.88^{* *}$ & 0.76 \\
Percent Unemployed & $1.81^{* *}$ & 0.81 \\
Female Headed & $1.85^{* *}$ & 0.80 \\
\hline
\end{tabular}

${ }^{*} p<0.01 ; * * p<0.001$

\section{DISCUSSION}

A geographically derived measure of the density of African American and Latino street gangs surrounding the population-weighted center of Los Angeles county zip codes was shown to independently influence homicide incidence over the study period, even after controlling for the well-known covariates of community homicide levels. This effect is cumulative, with higher densities of street gangs nearby equating to higher 8-year homicide incidence. Gang density, population density, unemployment rates, percent Latino, percent African American, and nearby high school dropout rates alone explained $90 \%$ of the variation observed among a $98.9 \%$ sample of $(10,880)$ homicides occurring in Los Angeles County between 1994 and 2002.

Los Angeles County is an expansive metropolitan area with more than nine million residents and wide variation in community characteristics. Latino and African American street gang activity has a strong influence on the elevated homicide rates in inner city areas in particular. These findings support the widely

TABLE 4 Multivariate relationships influencing homicide incidence by race/ethnicity

\begin{tabular}{lcccc}
\hline Variable & Overall effect & Black effect & Latino effect & White/other effect \\
\hline Population Density & $1.36^{* * *}$ & $0.41^{* * *}$ & $0.48^{* * *}$ & $0.65^{* * *}$ \\
Foster Care Rate & -0.09 & 0.01 & 0.00 & -0.05 \\
African American, Latino & $0.19^{* * *}$ & $0.12^{* *}$ & $0.16^{* * *}$ & $0.33^{* * *}$ \\
$\quad$ & & & \\
$\quad$ Street Gang Density & & & -0.01 & $0.23^{* * *}$ \\
High School Dropout Rate & $0.20^{*}$ & $0.07^{*}$ & & \\
$\quad$ within 5 miles & & & & -0.01 \\
Percent African American & $0.32^{* * *}$ & $0.65^{* * *}$ & $0.08^{* * *}$ & -0.09 \\
Percent Latino & $0.52^{* * *}$ & 0.07 & $0.55^{* * *}$ & -0.14 \\
Percent Ages 15-24 & 0.01 & -0.01 & -0.03 & $-0.38^{* *}$ \\
Median Income & 0.32 & 0.07 & 0.08 & 0.04 \\
Percent Unemployed & $0.55^{* *}$ & 0.07 & 0.11 & $-0.19^{*}$ \\
Female Headed & 0.26 & 0.02 & 0.02 & 0.52 \\
Adjusted $R^{2}$ & 0.90 & 0.89 & 0.90 & \\
\hline
\end{tabular}

${ }^{*} p<0.05 ;{ }^{* *} p<0.01 ; * * * p<0.001$ 
accepted contention that most instrumental and expressive gang killings originate from territorial/turf disputes between rival gangs. However, the observed relationships are also supportive of the notion that nearby street gang killings also result in diffusion of homicides into the nongang-affiliated population whose lives are clearly influenced by the activities of the gangs.

As previously discussed, street gang killings are unique in their characteristics and are more likely to occur in outside environments or in cars. One of the firmly established predictors of individual violent behavior is childhood exposure to violence. It could be that in gang-plagued areas, there is an entrenched psychosocial process that results from the cycle of excessive exposure to public gang violence and a correlating "spin-off" increase in other violence and nongang homicides in nearby areas. The fact that the presence of multiple nearby street gangs independently increases homicide rate in areas has important public health implications. Low income and minority families, in particular, are more likely to have their lives influenced by this cyclical relationship between unemployment, abandonment by and of the educational system, population density, street gang density, availability of handguns and automatic weapons, and elevated homicide rates.

The geographic boundaries of all of the African American gangs and virtually all of the Latino gangs were fixed long before the period of the study, thus negating the possibility that the relationship between outcome variable and the predictor variable was endogenous, and our study also controlled for the other known covariates of community homicide. Although our outcome variable was a long-term average of rates in particular places and the main predictor variable remained constant throughout the time period, the study was limited by reliance on some cross-sectional control variables. Another limitation of the study is that the coroner's data provided no information on the individual circumstances of each homicide, including whether it was determined to be "gang related" by a local police investigation. Additionally, the data contained very little about the individual characteristics of the victim other than race/ethnicity, gender, and age. These limitations place restrictions on the interpretation of the results but do not strongly influence the overall findings of the study.

Clearly, certain sections of Los Angeles County are more deadly environments for young persons living there, and inner city violence remains a major public health issue. Having higher numbers of high school dropouts and unemployed persons over 18 in densely populated inner city areas may put many young minority persons at elevated risk for being affected by street gangs, whether they choose to join a gang or not. Curing the problem will require greater coordination between local authorities, with more focused interventions coupled with the expansion of educational and employment possibilities for minority youth. The findings that the community covariates do not explain White homicide as strongly as Black and Latino homicide rates suggest that local social environments have greater influence on Black and Latino homicide patterns than those of Whites.

Given the mounting and compelling evidence on the role that street gangs play in accelerating the trajectory of lethal violence in urban areas, it follows to the extent that interventions targeted at reduction of gang membership and the surrender of street guns are bought into by local populations they may likely be effective in reducing the lethality of violent encounters within urban areas. Gun buy-back programs (typically offering higher payouts for automatic weaponry), and similar initiatives designed to take street guns out of local communities have had limited success in Los Angeles. In violent communities some weaponry may be sold back to 
government for money, but those active in the gang will likely keep enough guns to "do business". Gang injunctions are another popular yet controversial tactic used by local law enforcement authorities, and these have yielded mixed results as well. The effectiveness of gang injunctions are hindered by their local nature, and injunctions can actually increase inter-gang conflicts as gangs seek new markets in areas just outside the injunction boundaries. It becomes clear from the present study and other similar work that the processes that drive small area homicide trends in urban areas have become self-replicating through a cycle that includes the perceived threat of violence from external communities, the arming of local residents in response to that threat, and the resulting elevated levels of intentional injury mortality in certain neighborhoods within a given city.

Breaking this cycle will require a massive effort, akin to a "Marshall Plan" for inner city residents that improves public safety to the degree that local residents can actually buy into the idea that they can refuse to bear arms and remain safe in their communities. Obtaining this buy in will be hardest for young inner city minority youth, whose early lives are shaped by failing educational systems and lack of employment opportunities. Although these youth are not being prepared by their local institutions for participation in the "mainstream society", they will continue to live their lives, have their relationships, bear their offspring, and some of them will continue to feel the need to join the semi-organized criminal organizations that are the Bloods, Crips, Surenos, Mara Salvatrucha, and other gangs. Without addressing the social disorganization, lack of formal social control, and chronic failure of social institutions such as K-12 schooling systems that plague inner city areas of America's largest metropolises, there will be no stopping of the "gang problem" and the violence that it begets.

\section{ACKNOWLEDGMENT}

Paul Robinson, Kevin Heslin, Sheba George, W. John Boscardin and Ricky Bluthenthal received support from the UCLA/DREW Project Export, NCMHD, P20MD00148/P20MD000182. Paul Robinson, Kevin Heslin and Sheba George received support from Charles Drew University MRISP, AHRQ, HS014022. The authors would like to acknowledge Alejandro Alonso for his data support and expert consultation and Daniel Ryan for his technical support.

OPEN ACCESS This article is distributed under the terms of the Creative Commons Attibution Noncommercial Licence which permits any noncommercial use, distribution, and reproduction in any medium, provided the original author(s) and source are credited.

\section{REFERENCES}

1. Centers for Disease Control. National Center for Healthcare Statistics: Annual Leading Causes of Death Report. Hyattsville, MD: Centers for Disease Control; 2003.

2. Blumstein A, Rivara F, Rosenfeld R. The rise and decline of homicide-and why. Annu Rev Public Health. 2000;21:505-541. doi:10.1146/annurev.publhealth.21.1.505.

3. Gjelsvik A, Zierler S, Blume J. Homicide risk across race and class: a small-area analysis in Massachusetts and Rhode Island. J Urban Health. 2004;81(4):702-718. doi:10.1093/ jurban/jth152.

4. Martinez R. Latino Homicide: Immigration, Violence, and Community. New York: Routledge; 2002. 
5. Titterinton V, Vollum S, Diamond P. Neighborhoods and homicide: sex- and type-specific variation across three cities. Homicide Stud. 2003;7:263-288. doi:10.1177/108876 7903253622.

6. Messner S, Rosenfeld R. Political restraint of the market and levels of criminal homicide. Soc Forces. 1997;75(4):1393-416. doi:10.2307/2580676.

7. Parker K, McCall P, Land K. Determining social-structural predictors of homicide: units of analysis and methodological concerns. In: Smith, Zahn, eds. Homicide: A Sourcebook for Social Research. Thousand Oaks: Sage; 1998:107-124.

8. Scribner R, Cohen D, Kaplan S, Allen SH. Alcohol availability and homicide in New Orleans: conceptual considerations for small area analysis of the effect of alcohol outlet density. J Stud Alcohol. 1999;60:310-316.

9. Treno A, Gruenewald P, Johnson F. Alcohol availability and injury: the role of local outlet densities. Alcohol Clin Exp Res. 2001;25(10):1467-1471. doi:10.1111/j.1530-0277. 2001.tb02148.x.

10. LaVeist T, Wallace J. Health risk and inequitable distribution of liquor stores in African American neighborhood. Soc Sci Med. 2000;51:613-617. doi:10.1016/S0277-9536(00) 00004-6.

11. Strom K, MacDonald J. The influence of social and economic disadvantage on racial patterns in youth homicide over time. Homicide Stud. 2007;11:50-69. doi:10.1177/ 1088767906296199.

12. Phillips J. Variations in African-American homicide rates: an assessment of potential explanations. Criminology. 1997;35:527-559. doi:10.1111/j.1745-9125.1997.tb01229.x.

13. Shihadeh E, Ousey G. Industrial restructuring and violence: the link between entry-level jobs, economic deprivation, and Black and White homicide. Soc Forces. 1998;77:185206. doi:10.2307/3006014.

14. Shihadeh E, Flynn N. Segregation and crime: the effect of Black social isolation on the rates of Black urban violence. Soc Forces. 1996;74(4):1325-1352. doi:10.2307/2580353.

15. Peterson R, Krivo L. Macrostructural analyses of race, ethnicity, and violent crime: recent lessons and new directions for research. Annu Rev Sociol. 2005;31:331-356. doi:10.1146/annurev.soc.31.041304.122308.

16. Peterson R, Krivo L, Harris M. Disadvantage and neighborhood violent crime: do local institutions matter? J Res Crime Delinq. 2000;37(1):31-63. doi:10.1177/0022427 800037001002.

17. Messner S, Rosenfeld R. Social structure and homicide: theory and research. In: Smith A, Zahn A, eds. Homicide: A Sourcebook of Social Research. Thousand Oaks, CA: Sage; 1999:27-41.

18. Sampson R, Groves B. Community structure and crime: testing social-disorganization theory. Am J Sociol. 1989;94:774-802. doi:10.1086/229068.

19. Kornhauser R. Social Sources of Delinquency: An Appraisal of Analytic Models. Chicago: University of Chicago Press; 1978.

20. Braithwaite R, Taylor S. Health Issues in the Black Community. San Francisco: JosseyBass; 2001.

21. Bellair P. Social interaction and community crime: examining the importance of neighbor networks. Criminology. 1997;35:677-704. doi:10.1111/j.1745-9125.1997.tb01235.x.

22. Kubrin C, Wadswort T. Identifying the structural correlates of African American killings: what can we learn from data disaggregation? Homicide Stud. 2003;7:3-35. doi:10.1177/ 1088767902239241.

23. Kim S, Pridemore W. Poverty, socioeconomic change, institutional anomie, and homicide. Soc Sci Q. 2005;86:1377-1398. doi:10.1111/j.0038-4941.2005.00351.x.

24. Batten C, Jensen G. Decommodification and homicide rates in the 20th century United States. Homicide Stud. 2002;6:6-38. doi:10.1177/1088767902006001002.

25. De Robertis M, Litrownik A. The experience of foster care: relationship between foster parent disciplinary approaches and aggression in a sample of young foster children. Child Maltreat. 2004;9(1):92-102. doi:10.1177/1077559503260402. 
26. Freedman D, Hemenway D. Precursors of lethal violence: a death row sample. Soc Sci Med. 2000;50:1757-1770. doi:10.1016/S0277-9536(99)00417-7.

27. Resnick M, Ireland M, Borowsky I. Youth violence perpetration: what protects? What predicts? Findings from the national longitudinal study of adolescent health. J Adolesc Health. 2004;35(5):424e1-424e10.

28. Jonson-Reid M, Barth R. From maltreatment report to juvenile incarceration: the role of child welfare services. Child Abuse Negl. 2000;24(4):505-520. doi:10.1016/S0145-2134 (00)00107-1.

29. Taussig H. Risk behaviors in maltreated youth placed in foster care: a longitudinal study of protective and vulnerability factors. Child Abuse Negl. 2002;26(11):1179-1199. doi:10. 1016/S0145-2134(02)00391-5.

30. Decker SH, Curry GD. Gangs, gang homicides, and gang loyalty: organized crimes or disorganized criminals. J Crim Justice. 2002;30:343-352. doi:10.1016/S0047-2352(02) 00134-4.

31. Hutson H, Anglin D, Kyriacou D, Hart J, Spears K. The epidemic of gang related homicides in Los Angeles County from 1979-1994. JAMA. 1995;274(13):1031-1036. doi:10.1001/jama.274.13.1031.

32. Kyriacou D, Huston H, Anglin D, Peek-Asa C, Kraus J. The relationship between socioeconomic factors and gang violence in the city of Los Angeles. J Trauma Inj Infect Crit Care. 1999;46(2):334-339. doi:10.1097/00005373-199902000-00023.

33. Block CR, Block R. Street Gangs and Crime. Research and Bulletin. Chicago, IL: Illinois Criminal Justice Information Authority; 1996.

34. Decker SH, Curry GD. Gangs, gang homicides, and gang loyalty: organized crimes or disorganized criminals. J Crim Justice. 2002;30:343-352. doi:10.1016/S0047-2352(02) 00134-4.

35. Maxson S. Gang homicide: a review and extension of the literature. In: Smith MD, Zahn MA, eds. Homicide: A Sourcebook of Social Research. Thousand Oaks, CA: Sage; 1999:239-254.

36. Decker SH, Curry GD. Gangs, gang homicides, and gang loyalty: organized crimes or disorganized criminals. J Crim Justice. 2002;30:343-352. doi:10.1016/S0047-2352(02)00134-4.

37. Griffiths E, Chavez J. Communities, street guns and homicide trajectories in Chicago, 1980-1995: merging methods for examining homicide trends across space and time. Criminology. 2004;42:4. doi:10.1111/j.1745-9125.2004.tb00541.x.

38. Tita G, Ridgeway G. The impact of gang formation on local patterns of crime. J Res Crime Delinq. 2007;44:208. doi:10.1177/0022427806298356.

39. Tita G, Cohen J. Measuring spatial diffusion of shots fired activity across city neighborhoods. In: Goodchild M, Janelle D, eds. Spatially Integrated Social Science. New York: Oxford University Press; 2004.

40. Tita G, Cohen J, Enberg J. An ecological study of the location of gang set space. Soc Probl. 2007;52:2.

41. Bray RRT, Egley A. Facilitating violence: a comparison of gang motivated, gang affiliated and nongang youth homicides. J Quant Criminol. 1999;15:4.

42. California Department of Justice, 2005.

43. US Census of Population and Housing, 2000. Available at http:/quickfacts.census.gov/ qfd/states/06/06037.html.

44. Alonso A. Racialized identities and the formation of Black gangs in Los Angeles. Urban Geogr. 2004;25(7):658-674. doi:10.2747/0272-3638.25.7.658.

45. Land C, McCall P, Cohen L. Structural covariates of homicide rates: are there any invariances across time and social space? Am J Sociol. 1990;95(4):922-963. doi:10.1086/229381.

46. Rappaport N, Thomas C. Recent research findings on aggressive and violent behavior in youth: implications for clinical assessment and intervention. J Adolesc Health. 2004;35:260-277.

47. Reiss A, Roth J, eds. Understanding and Preventing Violence, Vol. 3. Washington, DC: National Academy; 1994. 